\title{
Self-reported changes in physical activity, sedentary behavior, and screen time among informal caregivers during the COVID-19 pandemic
}

Mary L. Greaney ${ }^{1 *}$, Zachary J. Kunicki ${ }^{2}$, Megan M. Drohan ${ }^{3}$, Christie L. Ward-Ritacco ${ }^{4}$, Deborah Riebe ${ }^{4}$ and Steven A. Cohen ${ }^{1}$

\begin{abstract}
Background: Informal caregivers providing unpaid assistance may be vulnerable to changes in health behaviors due to modifications in caregiving during the COVID-19 pandemic. Therefore, this cross-sectional study explored self-reported changes in physical activity (PA), sedentary behavior, and screen time among informal caregivers providing care for older adults aged 50+ during the pandemic.

Methods: Study participants were recruited via Amazon's Mechanical Turk and reported their perceived changes (increased a lot, increased a little, remained the same, decreased a little, decreased a lot) in moderate-intensity PA (MPA), vigorous-intensity PA (VPA), sedentary behavior, and screen time (weekday and weekend) during the pandemic. For analytic purposes, response categories were categorized into three-level ordinal variables-increased (increased a lot, increased a little), no change (remained the same), decreased (decreased a little, decreased a lot). Multinomial logistic regression models assessed the likelihood of changes (vs. no change) in MPA, VPA, sedentary behavior, and screen time (weekday, weekend) based on caregiving and demographic characteristics.

Results: In total, 2574 individuals accessed the study link, 464 of whom did not meet eligibility requirements. In addition, people who completed $80 \%$ or less of the survey $(n=1171)$ and/or duplicate IP addresse $(n=104)$ were excluded, resulting in an analytic sample of $n=835$. The sample was $69 \%$ male, had a mean age of $34(S D=9.7)$, and $48 \%$ reported increased VPA, while 55\% reported increased MPA. The majority also reported increased sedentary behavior, as well as increased screen time. Respondents living with their care recipient were more likely to report increased weekday screen time (Odds Ratio $[O R]=1.55,95 \% \mathrm{Cl} 1.11-2.16)$ and sedentary behavior $(\mathrm{OR}=$ $1.80,95 \% \mathrm{Cl} 1.28-2.53)$ than respondents not living with the care recipient. Those living with their care recipient were also more likely to reported increased MPA $(\mathrm{OR}=1.64,95 \% \mathrm{Cl} 1.16-2.32)$, and VPA $(\mathrm{OR}=1.53,95 \% \mathrm{Cl} 1.09-$ 2.15), but also more likely to report a decrease in VPA (OR $=1.75,95 \% \mathrm{Cl} 1.14-2.70)$.
\end{abstract}

\footnotetext{
*Correspondence: mgreaney@uri.edu

'Department of Health Studies, University of Rhode Island, 25 West Independent Way, Kingston, Rhode Island 02881, USA

Full list of author information is available at the end of the article
}

(c) The Author(s). 2021 Open Access This article is licensed under a Creative Commons Attribution 4.0 International License, which permits use, sharing, adaptation, distribution and reproduction in any medium or format, as long as you give appropriate credit to the original author(s) and the source, provide a link to the Creative Commons licence, and indicate if changes were made. The images or other third party material in this article are included in the article's Creative Commons licence, unless indicated otherwise in a credit line to the material. If material is not included in the article's Creative Commons licence and your intended use is not permitted by statutory regulation or exceeds the permitted use, you will need to obtain permission directly from the copyright holder. To view a copy of this licence, visit http://creativecommons.org/licenses/by/4.0/. The Creative Commons Public Domain Dedication waiver (http://creativecommons.org/publicdomain/zero/1.0/) applies to the data made available in this article, unless otherwise stated in a credit line to the data. 
Conclusion: The majority of respondents reported that their MPA, VPA PA, sedentary behavior, and screen time had changed during the pandemic. Living with the care recipient was associated with both positive and negative changes in behavior. Future research can explore factors associated with these reported changes in behavior.

Keywords: COVID-19, Informal caregivers, Physical activity, Screen time, Sedentary behavior

The World Health Organization declared COVID-19 a pandemic in March 2020 [1, 2], and efforts to curtail the pandemic have included closing public venues, sheltering in place, practicing social distancing, and restricting visitors to nursing homes and long-term care facilities [3]. There is a growing body of research suggesting that the COVID-19 pandemic has negatively impacted participation in healthful behaviors, including physical activity (PA) [4-6].

An estimated 41 million people in the United States are informal caregivers, individuals who provide unpaid care or assistance to older adults, persons with disabilities, and individuals requiring assistance [7], and this number will likely grow due to the increasing prevalence of chronic diseases and population aging [8]. A study analyzing Behavioral Risk Factor Surveillance System (BRFSS) data from 44 states, Washington DC, and Puerto Rico found that between 2015 and 2017 approximately $20 \%$ of respondents had provided care for a relative or friend in the last month [8]. Being an informal caregiver has associated benefits such as feeling closer to the care recipient $[9,10]$ and finding purpose in being a caregiver [11]. However, research also indicates that informal caregivers may have higher levels of stress and depression, as well as lower levels of subjective wellbeing and physical health, compared to non-caregivers [12-14].

Research shows caregiver burden and caregiving intensity may negatively impact caregivers' ability to engage in healthy behaviors [15], and increase caregiver risk of poor health and chronic diseases [15, 16]. For example, recent research conducted in Poland found that informal caregivers have less time for PA, hobbies, and their social lives, especially those who reside with their care recipient, compared to non-caregivers [17]. It is of public health concern that informal caregivers may be limited in their ability to engage in PA due to its positive association with mental health [18], and many other wellknown benefits including decreased risk for all-cause mortality and cardiovascular disease [19], some cancers [20], depression [21], and weight loss maintenance [22]. On the other hand, prolonged periods of sedentary behavior (SB, [e.g., sitting, watching television]) have negative impacts on health $[23,24]$, including elevated risks of all-cause mortality [24].

There is concern that the ongoing COVID-19 pandemic may negatively impact informal caregivers' participation in health-promoting behaviors and their health status [25], and research is needed to determine if intervention efforts are needed. Informal caregivers may be particularly vulnerable to changes in behaviors during the ongoing pandemic. Efforts to curtail the spread and impacts of COVID-19 likely resulted in changes in caregiving responsibilities for informal caregivers, including increases in caregiving responsibilities and caregiver burden and strain [25] and impacts on physical and mental health and health-related quality of life [26, 27]. Informal caregivers have reported that caregiver burden has increased during the pandemic $[28,29]$. Therefore, the aim of the current exploratory study was to determine if informal caregivers for older adults perceived that their health behaviors (moderate-intensity PA [MPA], vigorous-intensity $\mathrm{PA}[\mathrm{VPA}], \mathrm{SB}$, weekday screen time [ST], and weekend ST) had changed since the start of the pandemic. It has been hypothesized that there would be an increase in negative health behaviors (e.g., SB and ST) and a decrease in positive health behaviors (e.g., PA) due to changes in informal caregiving responsibilities that occurred as a result of efforts to curtail the spread of COVID-19.

\section{Methods}

Study participants were recruited in June 2020 using Amazon's Mechanical Turk (MTurk), an online platform/labor market that is used to recruit study participants globally for social and behavioral science research [30-32]. Registered MTurk users, referred to as workers, complete Human Intelligence Tasks (HITs), surveys and/or tasks, for a small incentive. Registered users $\log$ in to the MTurk online platform where they can access a list of HITs that they may be eligible to complete. The HIT for the current study was posted on the MTurk platform. Interested individuals accessing a link to Qualtrics where they accessed the informed consent document, provided informed consent, and completed questions assessing eligibility, which included being an informal caregiver for an individual 50 years or older with a health condition, disability, or cognitive decline, living in the United States, and being able to read English. Participants received $\$ 1.50$ for their effort and the study was approved by the Institutional Review Board at the University of Rhode Island (study \# 1606088-2). 


\section{Measures}

\section{Outcome measures}

The five outcome measures were self-reported changes in behaviors due to the pandemic: change in MPA, change in VPA, change in SB, change in weekday ST, and change in weekend (Saturday, Sunday) ST. Participants reported if they felt their participation in these behaviors had decreased a lot, decreased a little, remained the same, increased a little, or increased a lot since the start of the COVID-19 pandemic. Due to the novel nature of the pandemic and the lack of existing measures assessing perceived change in behavior due to the COVID-19, the outcomes measures were created for this current study. For analytic purposes, response categories were categorized into three-level ordinal variables-increased (increased a lot, increased a little), no change (remained the same), decreased (decreased a little, decreased a lot) due to small sample sizes in the "decreased a lot" categories), which would have left empty cells using multivariable regression models (MPA $[n=26]$, VPA $[n=37]$, SB $[n=12]$, weekday ST $[n=11]$, and weekend ST $[n=17])$.

\section{Covariates}

Covariates included the caregiver's gender (male, female), age, ethnicity (non-Hispanic, Hispanic), household income $(<\$ 15,000, \quad \$ 15,000<\$ 50,000, \quad \$ 50$, $000<\$ 75,000, \$>75,000)$, and if they had ever been diagnosed with COVID-19 (yes, no). Respondents also reported their racial identify, which based on the distribution of the data was dichotomized as White and Non-White. Caregivers also completed the 12-item Caregiver Burden Index (CBI), a multidimensional scale that estimates the amount of burden caregivers experience due to their caregiving [33]. Scores ranged from 0 to 43 and higher CBI scores indicate greater caregiver burden. The CBI was reliable in this sample $(\omega=.90)$.

Respondents' aerobic PA during the pandemic also was included as a covariate. It was assessed using the BRFSS PA module, a validated measure [34], that has been modified to be self-administered versus interviewer-administered $[35,36]$. Respondents completed the assessment of their PA before reporting their perceived changes in their MPA and VPA due to COVID-19. Two items assessed MPA, with the first item asking participants to report how many days (range 0-7) in a usual week that they did moderate activities for at least $10 \mathrm{~min}$ at a time, such as brisk walking, bicycling, vacuuming, gardening, or anything else that causes small increases in breathing or heart rate. The second item asked respondents to report the total time spent per day on MPA (On days when you do moderate activities for at least $10 \mathrm{~min}$ at a time, how much total time per day do you spend doing these activities?). VPA was assessed using two similar items. Reported minutes of MPA and VPA were summed into a total number of weekly minutes and then dichotomized as to whether a person met $(1=$ yes, $0=$ no $)$ the current recommendation put forth by the Centers for Disease Control and Prevention of $150+\min$ of MPA, or $75+\min$ of VPA, or an equivalent combination of both per week [19].

\section{Analysis}

The data were checked to ensure there was only one record per participant by checking IP addresses before analysis. If duplicate IP addresses were detected, only the first response was used for analysis. After selecting for covariates of interest, missing data diagnostics showed $2 \%$ of the data were missing. These data were imputed using multiple imputation with $m=10$ imputations. Multiple imputation was used to handle the missing data since it is a currently recommended technique which performs well when imputing categorical data [37]. Descriptive statistics were calculated for all study variables, including means and standard deviations for continuous measures and frequencies for categorical variables. Five separate multinomial logistic regression models, one for each behavior, were constructed to explore the relationships between the study covariates and the outcome variables. All models included covariates and the "no change" response option was the reference category in all multinomial regression models. This means the odds ratios (OR) for increases in behavior (MPA, VPA, SB, or ST) during the pandemic represent the likelihood of increases in behavior compared to "no change" in the examined behavior. Similarly, the ORs for decreases in behavior are compared to "no change" in the assessed behavior. Analyses were conducted using $\mathrm{R}$ version 4.0.2 ( $\mathrm{R}$ Core Team, 2020) using the mice package for imputation and nnet package for multinomial logistic regression [38, 39].

\section{Results}

In total, 2574 individuals accessed the study link: 464 of whom did not meet eligibility requirements. Additionally, people who completed $80 \%$ or less of the survey $(n=1171)$ and e duplicate IP addresses $(n=104)$ were excluded, resulting in an analytic sample of $n=835$.

The majority of the sample $(69 \%, n=572)$ was male, $45 \%(n=374)$ identified as Hispanic, $55 \%(n=457)$ identified as White, and 53\% ( $n=444)$ reported a COVID-19 diagnosis. Respondents average age was $34 \quad(\mathrm{SD}=10)$ years, and $41 \%(n=339)$ of respondents were living with their care recipient. See Table 1 for additional detail. With respect to health behaviors, 33\% $(n=272)$ of respondents were classified as meeting the current PA recommendation for aerobic exercise. 
Table 1 Description of Sample

\begin{tabular}{|c|c|c|}
\hline Characteristic & $N$ or Mean & $\%$ or $S D$ \\
\hline Age & 33.97 & 9.7 \\
\hline Caregiver Burden Index & 20.42 & 7.77 \\
\hline \multicolumn{3}{|l|}{ Lives with Care Recipient } \\
\hline Yes & 339 & $41 \%$ \\
\hline No & 496 & $59 \%$ \\
\hline \multicolumn{3}{|c|}{ Met Physical Activity Guidelines } \\
\hline Yes & 272 & $33 \%$ \\
\hline No & 563 & $67 \%$ \\
\hline \multicolumn{3}{|c|}{ Relationship to Care Recipient } \\
\hline Adult Child & 559 & $67 \%$ \\
\hline Spouse & 55 & $7 \%$ \\
\hline Other & 221 & $26 \%$ \\
\hline \multicolumn{3}{|l|}{ Gender Identity } \\
\hline Female & 263 & $31 \%$ \\
\hline Male & 572 & $69 \%$ \\
\hline \multicolumn{3}{|l|}{ Ethnicity } \\
\hline Non-Hispanic & 461 & $55 \%$ \\
\hline Hispanic & 374 & $45 \%$ \\
\hline \multicolumn{3}{|l|}{ Racial Identity } \\
\hline White & 457 & $55 \%$ \\
\hline Non-White & 378 & $45 \%$ \\
\hline \multicolumn{3}{|l|}{ Income } \\
\hline$<\$ 15,000$ & 131 & 16 \\
\hline$\$ 15,000<\$ 50,000$ & 230 & 28 \\
\hline$\$ 50,000<\$ 75,000$ & 173 & 21 \\
\hline$\$>75,000$ & 301 & 36 \\
\hline \multicolumn{3}{|l|}{ COVID-19 Diagnosis } \\
\hline Yes & 444 & $53 \%$ \\
\hline No & 391 & $47 \%$ \\
\hline
\end{tabular}

Overall, 55\% $(n=459)$ of respondents reported an increase in MPA, while 29\% $(n=244)$ reported no change, and $16 \%(n=132)$ reported a decrease. Model 1 examined changes in MPA and revealed that women were more likely than men to report an increase (vs. no change) in MPA (OR $=1.03,95 \%$ CI: 1.01, 1.04). In addition, respondents who reported living with their care recipient $(\mathrm{OR}=1.64,95 \% \mathrm{CI}: 1.16,2.32)$ were more likely to report an increase in MPA (vs. no change) than respondents who were not living with the care recipient, as were respondents who had reported COVID-19 diagnosis $(\mathrm{OR}=1.48,95 \% \mathrm{CI}: 1.04,2.12)$. No other significant results emerged (see Table 2).

Across the sample, $48 \%(n=403)$ of respondents reported an increase in VPA, while 33\% $(n=278)$ reported no change, and $18 \%(n=154)$ reported a decrease. Model 2 examined reported changes in VPA and determined that participants who had been diagnosed with COVID-19 (OR $=1.68,95 \% \mathrm{CI}: 1.18,2.38)$, and those who reported higher levels of caregiver burden as assessed by the Caregiver Burden Index (OR $=1.03$, 95\% CI: $1.00,1.05)$ were also more likely to report in an increase (vs. no change) in VPA. Participants who reported living with their care recipient were more likely to report increased (OR $=1.53,95 \% \mathrm{CI}: 1.09,2.15)$, or decreased $(\mathrm{OR}=1.75,95 \% \mathrm{CI}: 1.14,2.79)$ VPA (vs. no change). There were no other significant associations (see Table 2).

In total, $63 \%(n=526)$ of study participants reported an increase in SB, while $28 \%(n=237)$ reported no change, and $16 \%(n=132)$ reported a decrease. Model 3 assessed changes in SB and showed that participants who reported living with their care recipient $(\mathrm{OR}=1.80$, $95 \%$ CI: $1.28,2.53)$ were more likely to report increased SB (vs. no change) compared to respondents not living with the care recipient. No other significant results emerged (see Table 3).

More than half of respondents $(61 \%, n=510)$ reported that their weekday ST had increased, while $30 \%(n=$ 253) reported no change, and $9 \%(n=72)$ reported their weekday ST had decreased. Model 4 examined changes in weekday ST and found that participants who lived with their care recipient $(\mathrm{OR}=1.55,95 \% \mathrm{CI}: 1.11,2.16)$ had higher odds of increased weekday ST (vs. no change). In addition, over half $(57 \% n=453)$ of respondents reported that their weekend ST had increased, while $33 \%(n=278)$ reported no change, and 10\% $(n=$ 80) reported a decrease. The results of Model 5 examined changes in weekend ST and revealed that participants who reported a COVID-19 diagnosis had higher odds $(\mathrm{OR}=1.99,95 \% \mathrm{CI}: 1.13,3.53)$ of reporting a decrease in weekend ST. As seen in Table 4, no other significant associations were identified for weekday or weekend ST.

\section{Discussion}

A positive finding of the current study was that $48 \%$ of respondents reported that their VPA increased and 55\% reported increased MPA. Similarly, although different PA measures were used, a study with adults $(80 \%$ White, 15\% with a COVID-19 diagnosis) from the United Kingdom (UK) found that $47 \%$ of participants reported exercising more during the social lockdown, while 35\% stated that they were exercising less [40]. Another UK study found that a smaller percentage of respondents (11\%) reported being more physically active, while $25 \%$ reported doing less PA during lockdown [41]. Neither of these studies assessed caregiving status. Other studies also report that PA participation has declined during the pandemic [42]. 
Table 2 Multinomial Logistic Regression of Self-Reported Changes in Caregivers' Physical Activity (PA)

\begin{tabular}{|c|c|c|c|c|}
\hline \multirow[b]{3}{*}{ Caregiver variables } & \multicolumn{2}{|l|}{ Moderate PA } & \multicolumn{2}{|l|}{ Vigorous PA } \\
\hline & \multicolumn{2}{|c|}{ Odds Ratios (95\% Confidence Interval) } & \multicolumn{2}{|c|}{ Odds Ratios (95\% Confidence Interval) } \\
\hline & Decreased & Increased & Decreased & Increased \\
\hline \multicolumn{5}{|l|}{ Gender } \\
\hline Male & Ref & Ref & Ref & Ref \\
\hline Female & $1.10(.70-1.74)$ & $1.00(.71-1.42)$ & $1.44(.94-2.21)$ & $1.14(.80-1.61)$ \\
\hline Age & $1.01(.98-1.03)$ & $1.03^{* *}(1.01-1.04)$ & $1.00(.98-1.02)$ & $1.01(.99-1.03)$ \\
\hline \multicolumn{5}{|l|}{ Ethnicity } \\
\hline Non-Hispanic & Ref & Ref & Ref & Ref \\
\hline Hispanic & $.84(.52-1.34)$ & $1.33(.94-1.88)$ & $.72(.46-1.14)$ & $1.33(.95-1.87)$ \\
\hline \multicolumn{5}{|l|}{ Race } \\
\hline White & Ref & Ref & Ref & Ref \\
\hline Non-White & $.88(.55-1.42)$ & $1.31(.92-1.85)$ & $.78(.50-1.22)$ & $1.13(.80-1.58)$ \\
\hline \multicolumn{5}{|l|}{ Household income } \\
\hline$<\$ 15,000$ & Ref & Ref & Ref & Ref \\
\hline$\$ 15,000-\$ 50,000$ & $1.11(.54-2.30)$ & $.82(.49-1.38)$ & $1.84(.92-3.67)$ & $1.00(.61-1.63)$ \\
\hline$\$ 50,001-\$ 75,000$ & $1.00(.45-2.19)$ & $1.08(.62-1.88)$ & $1.35(.65-2.82)$ & $1.02(.60-1.73)$ \\
\hline$\$>75,000$ & $1.34(.67-2.68)$ & $.87(.52-1.45)$ & $1.75(.89-3.42)$ & $1.17(.72-1.90)$ \\
\hline \multicolumn{5}{|l|}{ COVID-19 diagnosis } \\
\hline No & Ref & Ref & Ref & Ref \\
\hline Yes & $1.07(.66-1.72)$ & $1.48^{*}(1.04-2.12)$ & $.81(.52-1.28)$ & $1.68^{* *}(1.18-2.38)$ \\
\hline CBI score & $.98(.95-1.01)$ & $.99(.97-1.01)$ & $1.00(.98-1.03)$ & $1.03^{*}(1.00-1.05)$ \\
\hline \multicolumn{5}{|c|}{ Met PA recommendation ${ }^{a}$} \\
\hline No & Ref & Ref & Ref & Ref \\
\hline Yes & $.96(.57-1.61)$ & $1.36(.94-1.96)$ & $.86(.52-1.41)$ & $1.27(.89-1.81)$ \\
\hline \multicolumn{5}{|c|}{ Lives with care recipient } \\
\hline No & Ref & Ref & Ref & Ref \\
\hline Yes & $1.33(.84-2.12)$ & $1.64^{* *}(1.16-2.32)$ & $1.75^{*}(1.14-2.70)$ & $1.53^{*}(1.09-2.15)$ \\
\hline \multicolumn{5}{|c|}{ Relationship to care recipient } \\
\hline Adult child & Ref & Ref & Ref & Ref \\
\hline Spouse & $.88(.29-2.66)$ & $1.77(.87-3.60)$ & $.88(.36-2.17)$ & $1.03(.54-1.96)$ \\
\hline Other & $1.20(.73-1.99)$ & $1.15(.78-1.69)$ & $1.57(.97-2.53)$ & $1.41(.96-2.07)$ \\
\hline
\end{tabular}

The "no change" category was used as the reference group; ${ }^{a} 150$ minutes of moderate PA/week or 75 min of vigorous PA/week, or an equivalent combination of the two/week; ${ }^{*}=p<.05,{ }^{* *}=p<.01$

Respondents living with their care recipient were more likely to report changes to their VPA in either a positive or negative direction. The reason for this inconsistent finding is unclear. It may well be that informal caregivers are exercising more because they have additional time to do so. It is possible that increased VPA is due to increased caregiving commitments due to the lack of paid support during the pandemic, as caregiver burden (as measured by the CBI) also was associated with a reported increase in VPA. It is also possible that respondents who had been diagnosed with COVID-19 had a decrease in cardiopulmonary function and as a result perceived their MPA as VPA. It also is possible, although not assessed in this study, that for some respondents participation in VPA declined due to efforts to stem the pandemic that inhibited their ability to be physically active (e.g..., sheltering at home, closing of gyms and health clubs).

Respondents living with their care recipients were also more likely to report an increase in SB compared to those not living with the person for whom they were providing care. Caregiving burden may impact the health-promoting behaviors of caregivers [43], and prior research suggests that co-residence of caregivers and care recipients may increase $\mathrm{CB}$ to some extent [44]. The increase in SB could also be due to spending more 
Table 3 Multinomial Logistic Regression of Self-Reported Changes in Caregivers' Sedentary Behavior

\begin{tabular}{|c|c|c|}
\hline \multirow[b]{2}{*}{ Caregiver Variable } & \multicolumn{2}{|c|}{ Odds Ratios ( $95 \%$ Confidence Interval) } \\
\hline & Decreased & Increased \\
\hline \multicolumn{3}{|l|}{ Gender } \\
\hline Male & Ref & Ref \\
\hline Female & $1.28(.72-2.27)$ & $1.22(.87-1.73)$ \\
\hline Age & $.98(.95-1.01)$ & $1.00(.99-1.02)$ \\
\hline \multicolumn{3}{|l|}{ Ethnicity } \\
\hline Non-Hispanic & Ref & Ref \\
\hline Hispanic & $.69(.38-1.25)$ & $1.19(.85-1.67)$ \\
\hline \multicolumn{3}{|l|}{ Race } \\
\hline White & Ref & Ref \\
\hline Non-White & $1.13(.63-2.04)$ & $1.37(.97-1.92)$ \\
\hline \multicolumn{3}{|l|}{ Household income } \\
\hline$<\$ 15,000$ & Ref & Ref \\
\hline$\$ 15,000-\$ 50,000$ & $1.37(.49-3.85)$ & $.69(.41-1.16)$ \\
\hline$\$ 50,001-\$ 75,000$ & $1.38(.47-4.05)$ & $.65(.37-1.13)$ \\
\hline$\$>75,000$ & $1.71(.63-4.67)$ & $.70(.42-1.16)$ \\
\hline \multicolumn{3}{|l|}{ COVID-19 diagnosis } \\
\hline No & Ref & Ref \\
\hline Yes & $.75(.42-1.37)$ & $.99(.70-1.40)$ \\
\hline CBI score & $1.04(1.00-1.07)$ & $1.00(.98-1.02)$ \\
\hline \multicolumn{3}{|c|}{ Met PA recommendation ${ }^{a}$} \\
\hline No & Ref & Ref \\
\hline Yes & $1.03(.56-1.89)$ & $.91(.64-1.30)$ \\
\hline \multicolumn{3}{|c|}{ Lives with care recipient } \\
\hline No & Ref & Ref \\
\hline Yes & $1.29(.72-2.31)$ & $1.80^{* *}(1.28-2.53)$ \\
\hline \multicolumn{3}{|c|}{ Relationship to care recipient } \\
\hline Adult Child & Ref & Ref \\
\hline Spouse & $.74(.23-2.36)$ & $.97(.51-1.84)$ \\
\hline Other & $.89(.46-1.74)$ & $1.25(.86-1.82)$ \\
\hline
\end{tabular}

The no change category was used as the reference group; ${ }^{\mathrm{a}} 150$ minutes of moderate PA/week or 75 min of vigorous PA/week, or an equivalent combination of the two/week; ${ }^{* *}=p<.01$

time with the care recipient due to less outside caregiving support and this could involve sedentary activities such as watching TV and talking or decreases in PA.

More than half $(53 \%)$ of respondents reported that they had been diagnosed with COVID-19, which was associated with reported increases in MPA and VPA, and weekend ST during the pandemic. It is possible that the COVID-19 diagnosis served as a cue to action and motivated respondents who had been diagnosed to improve their PA behaviors or they perceived their activity as more strenuous than before due to their illness as discussed previously.
A limitation of the study is that COVID-19 diagnosis is based on self-reported data and that the date of diagnosis and severity of symptoms is not known. It should be noted that the sample reported a substantially higher cumulative incidence (53\%) of having COVID-19 than the public, especially considering the data were collected during the early months of the pandemic (June 2020). It may be that caregivers who had been diagnosed with COVID-19 were more interested in participating in the study than those who had not had COVID-19. The sample was $69 \%$ male and prior research indicates that women are more likely to be informal caregivers than men [45]. Furthermore, some research conducted prepandemic has found that the majority of MTurk workers are women [46]: however, recent research revealed that during the pandemic more males than female participate in social science HITs [47]. These factors limit the generalizability of study findings. Other study limitations include the cross-sectional study design, reliance on selfreport measures that were developed for this study, use of a convenience sample of MTurk respondents, and limiting the sample to individuals with internet access. Some research does suggest that MTurk respondents are younger, have lower incomes, and are less likely to be Black than average Americans [48, 49] Nonetheless, research indicates that online convenience samples tend to provide valid results for research [48, 50]. Lastly, the data were collected in June 2020, the early stages of the pandemic, and PA, SB, and ST may have changed since the survey was conducted due to changes in pandemic severity and season [51].

The study has several strengths. It is novel in that it is one of the first studies to explore changes in the health behaviors of informal caregivers, who serve a vital role in the US healthcare system due to the pandemic. Additionally, the sample is relatively large. Moreover, we surveyed several different forms of the behaviors of interest (i.e., three measures of SB, two measures of PA) to allow for a comprehensive exploration among information caregivers of how the pandemic may influence health behaviors related to PA and ST. Future research should focus on uncovering the reasons for the seemingly contradictory findings that living with a care recipient was associated with both increased and decreased likelihood of VPA. It may well be that there are underlying subgroups that could help determine which respondents are more likely to report increased or decreased VPA and uncovering these subgroups may help inform interventions to promote health behaviors in the subgroups that reported decreased healthy behaviors. For example, it could be it could be the type of illness/condition their care giving recipient has that impacts VPA, caregiving for people who need help showering and toileting is different than caregiving for people who do not this type of 
Table 4 Multinomial Logistic Regression of Self-Reported Changes in Caregivers' Weekday and Weekend Screen Time

\begin{tabular}{|c|c|c|c|c|}
\hline \multirow[b]{3}{*}{ Caregiver Variables } & \multicolumn{2}{|c|}{ Weekday Screen Time } & \multicolumn{2}{|c|}{ Weekend Screen Time } \\
\hline & \multicolumn{2}{|c|}{ Odds Ratios (95\% Confidence Interval I) } & \multicolumn{2}{|c|}{ Odds Ratios (95\% Confidence Intervall) } \\
\hline & Decreased & Increased & Decreased & Increased \\
\hline \multicolumn{5}{|l|}{ Gender } \\
\hline Male & Ref & Ref & Ref & Ref \\
\hline Female & $1.30(.74-2.28)$ & $1.06(.75-1.49)$ & $1.06(.62-1.81)$ & $.80(.58-1.10)$ \\
\hline Age & $.99(.97-1.02)$ & $1.00(.99-1.02)$ & $.99(.97-1.02)$ & $1.00(.98-1.01)$ \\
\hline \multicolumn{5}{|l|}{ Ethnicity } \\
\hline Non-Hispanic & Ref & Ref & Ref & Ref \\
\hline Hispanic & $.93(.52-1.65)$ & $1.23(.88-1.72)$ & $.82(.47-1.42)$ & $.92(.66-1.27)$ \\
\hline \multicolumn{5}{|l|}{ Race } \\
\hline White & Ref & Ref & Ref & Ref \\
\hline Non-White & $1.12(.62-2.01)$ & $1.29(.92-1.80)$ & $.62(.35-1.10)$ & $1.07(.77-1.47)$ \\
\hline \multicolumn{5}{|l|}{ Household income } \\
\hline$<\$ 15,000$ & Ref & Ref & Ref & Ref \\
\hline$\$ 15,000-\$ 50,000$ & $.77(.31-1.92)$ & $.63(.38-1.03)$ & $1.53(.57-4.16)$ & $.71(.44-1.14)$ \\
\hline$\$ 50,001-\$ 75,000$ & $1.00(.37-2.67)$ & $.87(.51-1.49)$ & $1.87(.66-5.31)$ & $1.00(.59-1.67)$ \\
\hline$\$>75,000$ & $1.71(.71-4.11)$ & $.98(.60-1.62)$ & $2.52(.96-6.61)$ & $.96(.60-1.53)$ \\
\hline COVID-19 diagnosis & & Ref & Ref & \\
\hline No & Ref & Ref & $1.53(.57-4.16)$ & $.71(.44-1.14)$ \\
\hline Yes & $0.99(.54-1.80)$ & $.83(.59-1.12)$ & $1.87(.66-5.31)$ & $1.00(.59-1.67)$ \\
\hline CBI score & $1.01(.97-1.05)$ & $.98(.96-1.00)$ & $2.52(.96-6.61)$ & $.96(.60-1.53)$ \\
\hline \multicolumn{5}{|c|}{ Met PA recommendation ${ }^{a}$} \\
\hline No & Ref & Ref & Ref & Ref \\
\hline Yes & $1.43(.80-2.55)$ & $.88(.62-1.25)$ & $.58(.32-1.07)$ & $1.03(.73-1.44)$ \\
\hline \multicolumn{5}{|c|}{ Lives with care recipient } \\
\hline No & Ref & Ref & Ref & Ref \\
\hline Yes & $.93(.51-1.68)$ & $1.55^{*}(1.11-2.16)$ & $1.10(.64-1.89)$ & $1.28(.93-1.77)$ \\
\hline \multicolumn{5}{|c|}{ Relationship to care recipient } \\
\hline Adult child & Ref & Ref & Ref & Ref \\
\hline Spouse & $2.04(.74-5.58)$ & $1.68(.84-3.36)$ & $1.59(.60-4.25)$ & $1.41(.73-2.72)$ \\
\hline Other & $1.02(.53-1.96)$ & $1.29(.89-1.88)$ & $.83(.44-1.57)$ & $.95(.66-1.36)$ \\
\hline
\end{tabular}

The "no change" category was used as the reference group; ${ }^{a} 150$ minutes of moderate PA/week or 75 min of vigorous PA/week, or an equivalent combination of the two/week; ${ }^{*}=p<.05$

assistance. These findings may also be an example of the Table 2 Fallacy [52], so future research in this area should consider using a causal inference approach to determine if these results are statistical or causal associations. Future research could also examine longitudinal changes in caregiving to determine if changes in supports and/or increases in caregiving are associated with changes in in informal caregivers' health behaviors.

\section{Conclusion and implications}

The majority of informal caregivers in the current study perceived that their SB, weekday ST, and weekend ST increased during the pandemic. The findings of the current study indicate a need to intervene on these behaviors among informal caregivers for older adults to return to pre-pandemic behaviors for those who reported an increase in negative health behaviors or a decrease in health promoting behaviors. In addition, intervention efforts could also be implemented to reinforce positive changes in behaviors. Special efforts should be given to informal caregivers who reside with their care recipient. Their health behaviors could be assessed at their medical appointments or when they accompany the care recipient to appointments. Assessments also could be done in 
person, via telehealth appointment, or online. Interventions that can be delivered remotely should be explored due to time constraints associated with caregiving.

\section{Acknowledgements}

We would like to thank all persons who participated in this study.

\section{Authors' contributions}

MLG and SAC conceptualized the study. ZJK and SAC defined the analysis. ZJK performed data analysis and constructed all tables. MLG drafted the manuscript. ZJK, SAC, MMD, CWR, and DR contributed to the drafting and revising of the manuscript. All Authors read, commented and approved the final manuscript.

\section{Funding}

This research received no specific grant from any funding agency in the public, commercial or not-for-profit sectors.

\section{Availability of data and materials}

The dataset analyzed for this current study are available from the corresponding author upon reasonable request.

\section{Declarations}

\section{Ethics approval and consent to participate}

The study was approved by the Institutional Review Board at The University of Rhode Island. All study participants provided informed consent prior to completing the survey. All methods were carried out in accordance with relevant guidelines and regulations.

\section{Consent for publication}

Not applicable. There are no images or videos as part of this publication.

\section{Competing interests}

Mary L. Greaney is a member of the BMC Editorial Board. Drs. Cohen, Kunicki, Riebe and Ward-Ritacco and Ms. Drohan declare that they have no competing interests.

\section{Author details}

'Department of Health Studies, University of Rhode Island, 25 West Independent Way, Kingston, Rhode Island 02881, USA. ${ }^{2}$ Department of Psychiatry and Human Behavior, Warren Alpert Medical School of Brown University, Providence, Rhode Island, USA. ${ }^{3}$ Department of Psychology, University of Rhode Island, Kingston, Rhode Island, USA. ${ }^{4}$ Department of Kinesiology, University of Rhode Island, Kingston, Rhode Island, USA.

Received: 10 March 2021 Accepted: 14 June 2021

Published online: 02 July 2021

\section{References}

1. Mahase E. Covid-19: WHO declares pandemic because of "alarming levels" of spread, severity, and inaction. 2020. BMJ;368:m1036.

2. Jebril N. World Health Organization declared a pandemic public health menace: a systematic review of the coronavirus disease 2019 "COVID-19", up to 26th March 2020. 2020. Available at SSRN 3566298. Available from: https://papers.ssrn.com/sol3/papers.cfm?abstract_id=3566298.

3. World Health Organization. World Health Organization Coronavirus Disease (COVID-19) Pandemic. Available online: https:/www.who.int/emergencies/ diseases/novel-coronavirus-2019. Accessed 13 Dec 2020.

4. Robinson E, Boyland E, Chisholm A, Harrold J, Maloney NG, Marty L, et al. Obesity, eating behavior and physical activity during COVID-19 lockdown: a study of UK adults. Appetite. 2021;156:104853. https://doi.org/10.1016/j.a ppet.2020.104853

5. Martínez-de-Quel Ó, Suárez-Iglesias D, López-Flores M, Pérez CA. Physical activity, dietary habits and sleep quality before and during COVID-19 lockdown: a longitudinal study. Appetite. 2021;158:105019. doi:https://doi. org/10.1016/.j.appet.2020.105019.

6. Tison GH, Avram R, Kuhar P, Abreau S, Marcus GM, Pletcher MJ, et al. Worldwide effect of COVID-19 on physical activity: a descriptive study. Ann Intern Med. 2020;173(9):767-70. https://doi.org/10.7326/M20-2665.
7. Reinhard SC, Feinberg LF, Houser A, Choula R, Evans M. Valuing the invaluable: 2019 update: charting a path forward. 2019. doi:https://doi.org/1 0.26419/ppi.00082.001.

8. Edwards VJ, Bouldin ED, Taylor CA, Olivari BS, McGuire LC. Characteristics and health status of informal unpaid caregivers - 44 states, District of Columbia, and Puerto Rico, 2015-2017. MMWR. 2020;69(7):183-8. https://doi. org/10.15585/mmwr.mm6907a2.

9. Lloyd J, Patterson T, Muers J. The positive aspects of caregiving in dementia: a critical review of the qualitative literature. Dementia. 2016;15(6):1534-61. https://doi.org/10.1177/1471301214564792.

10. Schulz R, Beach SR, Czaja SJ, Martire LM, Monin JK. Family caregiving for older adults. Annu Rev Psychol. 2020;71(1):635-59. https://doi.org/10.1146/a nnurev-psych-010419-050754.

11. Cherry MG, Ablett JR, Dickson JM, Powell D, Sikdar S, Salmon P. A qualitative study of the processes by which carers of people with dementia derive meaning from caring. Aging Ment Health. 2019;23(1):69-76. https://doi. org/10.1080/13607863.2017.1393792.

12. Pinquart M, Sörensen S. Differences between caregivers and noncaregivers in psychological health and physical health: a meta-analysis. Psychol Aging. 2003;18(2):250-67. https://doi.org/10.1037/0882-7974.18.2.250.

13. Pinquart M, Sörensen S. Correlates of physical health of informal caregivers: a meta-analysis. J Gerontol B Psychol Sci Soc Sci. 2007;62(2):P126-37. https://doi.org/10.1093/geronb/62.2.P126.

14. Treasure J. Review: exploration of psychological and physical health differences between caregivers and non-caregivers. Evidence-Based Mental Health. 2004;7(1):28. https://doi.org/10.1136/ebmh.7.1.28.

15. Mochari-Greenberger H, Mosca L. Caregiver burden and nonachievement of healthy lifestyle behaviors among family caregivers of cardiovascular disease patients. Am J Health Promot. 2012;27(2):84-9. https://doi.org/10.4278/a jhp.110606-QUAN-241.

16. Miyawaki CE, Bouldin ED, Taylor CA, MCGuire LC. Baby boomers as caregivers: results from the behavioral risk factor surveillance system in 44 states, the District of Columbia, and Puerto Rico, 2015-2017. Prev Chronic Dis. 2020;17:E80

17. Rokicka M, Zajkowska O. Informal elderly caregiving and time spent on leisure: evidence from time use survey. Ageing Int. 2020;45(4):393-410. https://doi.org/10.1007/s12126-020-09396-5.

18. Biddle S. Physical activity and mental health: evidence is growing. World Psychiatry. 2016:15(2):176-7. https://doi.org/10.1002/wps.20331.

19. Piercy KL, Troiano RP, Ballard RM, Carlson SA, Fulton JE, Galuska DA, et al. The physical activity guidelines for Americans. JAMA. 2018;320(19):2020-8. https://doi.org/10.1001/jama.2018.14854

20. Patel AV, Friedenreich CM, Moore SC, Hayes SC, Silver JK, Campbell KL, et al. American College of Sports Medicine roundtable report on physical activity, sedentary behavior, and cancer prevention and control. Med Sci Sports Exerc. 2019;51(11):2391-402. https://doi.org/10.1249/MSS.0000000000002117.

21. Teychenne M, Ball K, Salmon J. Sedentary behavior and depression among adults: a review. Int J Behav Med. 2010;17(4):246-54. https://doi.org/10.1007/ s12529-010-9075-Z.

22. Paixão C, Dias CM, Jorge R, Carraça EV, Yannakoulia M, de Zwaan M, et al. Successful weight loss maintenance: a systematic review of weight control registries. Obes Rev. 2020;21:e13003.

23. Owen N, Healy GN, Matthews CE, Dunstan DW. Too much sitting: the population health science of sedentary behavior. Exerc Sport Sci Rev. 2010; 38(3):105-13. https://doi.org/10.1097/JES.0b013e3181e373a2.

24. Biswas A, Oh PI, Faulkner GE, Bajaj RR, Silver MA, Mitchell MS, et al. Sedentary time and its association with risk for disease incidence, mortality, and hospitalization in adults: a systematic review and meta-analysis. Ann Intern Med. 2015;162(2):123-32. https://doi.org/10.7326/M14-1651.

25. Egan K. Digital technology, health and well-being and the Covid-19 pandemic: it's time to call forward informal carers from the back of the queue. Semin Oncol Nurs. 2020;36(6):151088. https://doi.org/10.1016/j. soncn.2020.151088.

26. Lightfoot E, Moone RP. Caregiving in times of uncertainty: helping adult children of aging parents find support during the COVID-19 outbreak. J Gerontol Soc Work. 2020;63(6-7):542-52. https://doi.org/10.1080/01634372.2020.1769793.

27. Park SS. Caregivers' mental health and somatic symptoms during COVID-19. J Gerontol B Psychol Sci Soc Sci. 2021;76(4):e235-40. https://doi.org/10.1 093/geronb/gbaa121.

28. Altieri M, Santangelo G. The psychological impact of COVID-19 pandemic and lockdown on caregivers of people with dementia. Am J Geriatr Psychiatry. 2021;29(1):27-34. https://doi.org/10.1016/j.jagp.2020.10.009. 
29. Budnick A, Hering C, Eggert S, Teubner C, Suhr R, Kuhlmey A, et al. Informal caregivers during the COVID-19 pandemic perceive additional burden: findings from an ad-hoc survey in Germany. BMC Health Serv Res. 2021; 21(1):353. https://doi.org/10.1186/s12913-021-06359-7.

30. MCCredie MN, Morey LC. Who are the Turkers? A characterization of MTurk workers using the personality assessment inventory. Assessment. 2019;26(5): 759-66. https://doi.org/10.1177/1073191118760709.

31. Mason W, Suri S. Conducting behavioral research on Amazon's mechanical Turk. Behav Res Methods. 2012;44(1):1-23. https://doi.org/10.3758/s13428011-0124-6.

32. Paolacci G, Chandler J. Inside the Turk: understanding mechanical Turk as a participant pool. Curr Dir Psychol Sci. 2014;23(3):184-8. https://doi.org/10.11 77/0963721414531598

33. Higginson IJ, Gao W, Jackson D, Murray J, Harding R. Short-form Zarit caregiver burden interviews were valid in advanced conditions. J Clin Epidemiol. 2010;63(5):535-42. https://doi.org/10.1016/j.jclinepi.2009.06.014.

34. Yore MM, Ham SA, Ainsworth BE, Kruger J, Reis JP, Kohl HW 3rd, et al. Reliability and validity of the instrument used in BRFSS to assess physical activity. Med Sci Sports Exerc. 2007;39(8):1267-74. https://doi.org/10.1249/ mss.0b013e3180618bbe.

35. Estabrooks PA, Bradshaw M, Dzewaltowski DA, Smith-Ray RL. Determining the impact of walk Kansas: applying a team-building approach to community physical activity promotion. Ann Behav Med. 2008;36(1):1-12. https://doi.org/10.1007/s12160-008-9040-0.

36. Emmons KM, Puleo E, Greaney ML, Gillman MW, Bennett GG, Haines J, et al. A randomized comparative effectiveness study of healthy directions 2--a multiple risk behavior intervention for primary care. Prev Med. 2014;64:96102. https://doi.org/10.1016/j.ypmed.2014.03.011.

37. Lang KM, Little TD. Principled missing data treatments. Prev Sci. 2018;19(3): 284-94. https://doi.org/10.1007/s11121-016-0644-5.

38. Van Buuren S, Groothuis-Oudshoorn K. Mice: multivariate imputation by chained equations in RJ Stat. Softw. 2011;45:1-67.

39. Ripley B, Venables W. nnet: Feed-forward neural networks and multinomial log-linear models. R package version 7.3-12; 2016.

40. Robinson E, Gillespie S, Jones A. Weight-related lifestyle behaviours and the COVID-19 crisis: an online survey study of UK adults during social lockdown. Obes Sci Pract. 2020;6(6):735-40. https://doi.org/10.1002/osp4.442.

41. Rogers NT, Waterlow N, Brindle HE, Enria L, Eggo RM, Lees S, et al. Behavioural change towards reduced intensity physical activity is disproportionately prevalent among adults with serious health issues or selfperception of high risk during the UK COVID-19 lockdown. 2020. doi:https:// doi.org/10.1101/2020.05.12.20098921.

42. Caputo EL, Reichert FF. Studies of physical activity and COVID-19 during the pandemic: a scoping review. J Phys Act Health. 2020;17(12):1275-84. https:// doi.org/10.1123/jpah.2020-0406.

43. Hirano A, Suzuki Y, Kuzuya M, Onishi J, Hasegawa J, Ban N, et al. Association between the caregiver's burden and physical activity in communitydwelling caregivers of dementia patients. Arch Gerontol Geriatr. 2011;52(3): 295-8. https://doi.org/10.1016/j.archger.2010.04.011.

44. Lau S, Chong MS, Ali N, Chan M, Chua KC, Lim WS. Caregiver burden: looking beyond the unidimensional total acore. Alzheimer Dis Assoc Disord. 2015;29(4):338-46. https://doi.org/10.1097/WAD.0000000000000085.

45. Cohen SA, Sabik NJ, Cook SK, Azzoli AB, Mendez-Luck CA. Differences within differences: gender inequalities in caregiving intensity vary by race and ethnicity in informal caregivers. J Cross Cult Gerontol. 2019;34(3):245-63. https://doi.org/10.1007/s10823-019-09381-9.

46. Ross J, Irani L, Silberman MS, Zaldivar A, Tomlinson B. Who are the crowdworkers? shifting demographics in mechanical turk. In: CHI '10 Extended Abstracts on Human Factors in Computing Systems. New York: Association for Computing Machinery; 2010. p. 2863-72.

47. Arechar AA, Rand DG. Turking in the time of COVID. Behav Res Methods. 2021. https://doi.org/10.3758/s13428-021-01588-4.

48. Berinsky AJ, Huber GA, Lenz GS. Evaluating online labor markets for experimental research: Amazon.com's Mechanical Turk. Polit Anal. 2012;20:351-68.

49. Koster A, Caserotti P, Patel KV, Matthews CE, Berrigan D, Van Domelen DR, et al. Association of sedentary time with mortality independent of moderate to vigorous physical activity. PLoS One. 2012;7(6)

50. Weinberg JD, Freese J, McElhattan D. Comparing data characteristics and results of an online factorial survey between a population-based and a crowdsource-recruited sample. Sociol Sci. 2014;1. https://sociologicalscience. com/download/volume\%201/august/SocSci_v1_292to310.pdf.
51. Turrisi TB, Bittel KM, West AB, Hojjatinia S, Hojjatinia S, Mama SK, et al. Seasons, weather, and device-measured movement behaviors: a scoping review from 2006 to 2020. Int J Behav Nutr Phys Act. 2021;18:24.

52. Westreich D, Greenland S. The table 2 fallacy: presenting and interpreting confounder and modifier coefficients. Am J Epidemiol. 2013;177(4):292-8. https://doi.org/10.1093/aje/kws412.

\section{Publisher's Note}

Springer Nature remains neutral with regard to jurisdictional claims in published maps and institutional affiliations.
Ready to submit your research? Choose BMC and benefit from:

- fast, convenient online submission

- thorough peer review by experienced researchers in your field

- rapid publication on acceptance

- support for research data, including large and complex data types

- gold Open Access which fosters wider collaboration and increased citations

- maximum visibility for your research: over $100 \mathrm{M}$ website views per year

At $\mathrm{BMC}$, research is always in progress.

Learn more biomedcentral.com/submissions 